\title{
Water Circulation and Climate Change
}

\author{
Oleg Khalidullin* \\ Academician of the Russian Federation LAN, Russia
}

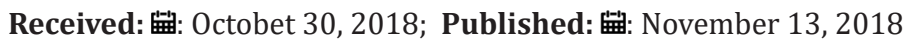

*Corresponding author: Oleg Khalidullin, Academician of the Russian Federation LAN, Russia

\section{Opinion}

Humanity annually takes away more and more lands from nature: plows it under crops, floods hydroelectric reservoirs, cuts down forests, concretes and asphalt areas of new cities and roads, falls asleep. "The total area of the dumps alone is approximately equal to the area of Mexico, to the three territories of Ukraine, or 5 territories of Germany" [1]. The total area of land killed in the world, according to various sources of information, ranges from 10 to 76 percent for 2015 . The essence is not the volumes, but the essence is that these areas are intensively growing, have become commensurate with the land area of the whole Earth and the time comes when it will become $100 \%$ - natural habitats disappear. All water evaporated from such territories, at best, does not change its structure. As they came with precipitation, they returned back to the atmosphere. At worst, they are impregnated and combined with chemical elements, which then, it happens that, with a strong concentration, they fall out of acid rain. Evaporations from degraded areas are substantially complemented by evaporations from technological processes of industrial and municipal production. Of all things, only man came up with using water for other purposes. Nature did not expect such volumes of evaporation from washing and drying clothes, dishes, asphalt, production processes everything that was created by civilization. All evaporation of water, which has not gone the way of transformation in living organisms and plants, is alien to nature, the cycle of natural transformations is shrinking, man-made them. Such evaporation can be called artificial.

Historically, the interaction of the plant and animal worlds with water has created atmospheric phenomena and a cycle with the transformation of water. Nature provides transitions of water from a liquid to a vapor. Falling out of sediments, one of the most important redistribution is carried out - water turns into plant sap, blood and flesh of animals and comes out of them by purely individual waste, which is evaporated in clouds, performs some specific role in the formation of clouds, winds and atmospheric pressure. It is possible that these parameters create a mechanism that creates special conditions under which precipitation accelerates to given places in specified volumes and at specified intervals. For millions of years, such a mechanism has been improved and stabilized with high accuracy, ensuring the formation of various zones: steppes, deserts, forests, tropics - the whole palette of geographical zones. In the most comfortable of them, man settled, created an industry and giant-scale artificial vapors without coordination with nature. The distortion of the natural functions of water affected the most important organs of the climate system - the accumulation of water in the polar and mountain glaciers. These are natural refrigerators which form the set temperature conditions. The reduction of glaciers at the poles of the Earth and in the mountains affects the weather and climate, creating global warming. Perhaps this factor is one of the key factors in climate change: "The Arctic zone is the leader in global warming. Here it happens much faster. It is expected that by the end of the 21st century, the air temperature will rise by another $7^{\circ} \mathrm{C}$. We carried out calculations and came to the conclusion that with a probability of $73 \%$ in August-September 2058, the Arctic will be completely free from the ice sheet for the first time in 100,000 years" [2].

As industrialization develops, artificial evaporation increases in volumes and speeds. The quality of evaporation is a little-studied direction of science, but, in all likelihood, it also has some effect on the "heavenly kitchen." Evaporations from drying asphalt and from the plant or from the breathing of an animal cannot be the same. The official hypothesis, based on carbon dioxide emissions, distracts the world community from the true cause of climate change and leads the world to a global catastrophe. Being engaged in microscopic reductions of emissions of $\mathrm{CO}_{2}$, we do not see the main reason. From the beginning of the $20_{\text {th }}$ century, according to UN experts [3], the increase in $\mathrm{CO}_{2}$ emissions ranged from 0.5 to $5 \%$ per year. As a result, over the past hundred years, 400 billion tons of carbon dioxide has just entered the atmosphere due to 
the burning of fuel" Or 4 billion tons per year. Much or little is known in comparison. What to compare? With water - the most voluminous material rising into the atmosphere. According to [4], up to 20 thousand cubic kilometers of groundwater are extracted annually. Plus, according to [5], people irrevocably take away about 2 thousand cubic kilometers of fresh water from rivers and lakes Annually.

All this water through sewers and evaporation goes into the atmosphere without organic changes. 22,000 cubic kilometers is 22 trillion cubic meters or tons of water. In this volume, 4 billion tons of CO2 is only $0.018 \%$. This is a drop in a glass. Can this drop - 0 , $018 \%$ affect something when in the sky there are 22 trillion tons of artificial evaporated? oi and taking into account natural evaporation - in terms of volumes, perhaps even more - the fight against carbon dioxide is a war with fleas. Increasing artificial evaporation unprecedented by nature in terms of volumes and speeds changed the "celestial kitchen", broke distribution mechanisms, schedules, and precipitation by zones of the earth's surface. In some places, devastating floods, in others - drought and fires. It was the change in the distribution of precipitation that affected the long-term accumulation of water in the glaciers - the growth of glaciers stopped. Without reaching the poles and mountain zones, the waters fall out of rain and snow not in historically given places, but in oceans and foothill zones.

The level of the oceans is growing from melting glaciers, but precipitations that fall outside the schedule, which were supposed to replenish glaciers, give a greater increase. "Currently, in 2013, the main source of fresh water continues to be the waters of rivers, lakes, artesian wells and the desalination of sea water. At the same time, if in all river beds there are 1.2 thousand cubic kilometers of water, then its amount in the atmosphere is 14 thousand cubic kilometers. Every year, 577 thousand cubic kilometers of water evaporates from the surface of the land and the ocean, and the same amount then falls as precipitation" [6]. If we accept that precipitation falls evenly across the planet, then $1 / 3$ of the land falls $192 \mathrm{~km} 3.22 \mathrm{~km} 3$ of them - this is about $10 \%$ of artificial evaporation alone. The water evaporates along the shortened chain of the water cycle between the atmosphere and the soil. And these fumes are growing with terrifying acceleration. New hydroelectric power stations are being designed and built around the world with the flooding of vast territories, rivers are turning and cities and roads are being built, agricultural areas are being processed, forests are being cut down, and new areas are being filled up with waste. The future of the planet is rather alarming.

Is there salvation? Do we want to continue the human race and in general life on the planet? It is necessary to return all taken away to nature: land and water. It is urgent to prove the assumptions made here and develop a new concept of saving life on the planet. It should be based on total saving of water in production and everyday life by every enterprise, every state, every person. It is not easy to make rules about forgotten tap and the reduction of water consumption. It is necessary to radically reconsider all actions related to water. Water must make a qualitative transition from the functions of the working fluid body, the reagent to the food product - drinking, and only to personal consumption - by living organisms. Everything else must be reduced.

\section{References}

1. Popular science site on meteorology, Vegetables cause global warming.

2. Popular science site on meteorology, Arctic ice change.

3. http://www.refsru.com/referat-17732-3

4. (2013) Global drought or water problems.

5. Oleg Halidullin (2018) About Climate Change. Cur Trends Civil \& Struct Eng TCSE.MS.ID.000504.

6. (2013) Global drought or water problems.

\section{ISSN: 2574-1241}

DOI: $10.26717 / B J S T R .2018 .10 .002027$

Oleg Khalidullin. Biomed J Sci \& Tech Res

This work is licensed under Creative Commons Attribution 4.0 License

Submission Link: https://biomedres.us/submit-manuscript.php

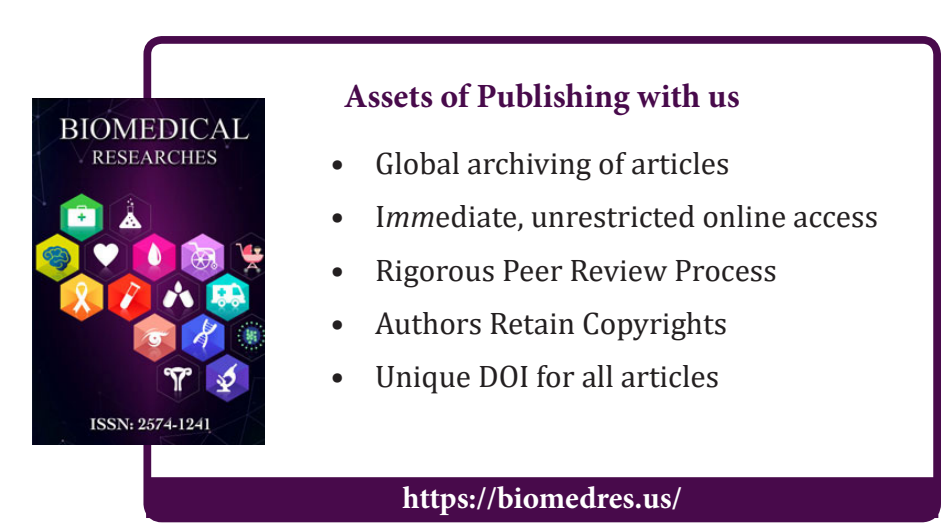

